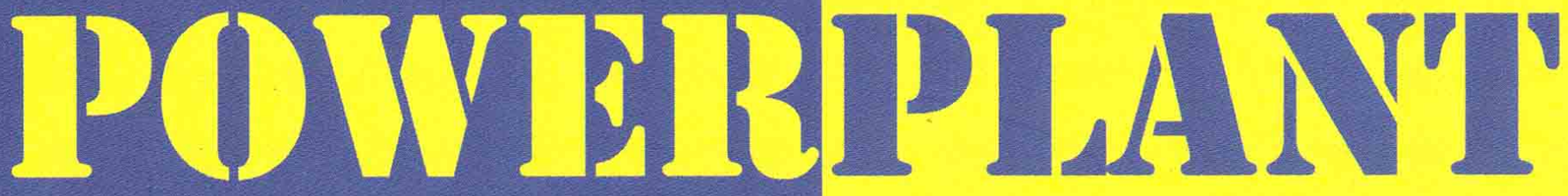

Nofirman:

Yusuf Rasyid

Vendy Antono;

Win Alfalah;

Rizky Windani

Eko Sulistiyo:

Utami Wahyuningsih:

M. Arif Rahman Sutisna

Sahlan

Vendy Antono;

Arief Suardi Nur Chairat;

Muhammad Husnuddin

Prayudi:

Roswati Nurhasanah

Hendri;

Suhengki:

Amru Fathony Lubis

Sri Yayi:

Jumiati;

Intan Ratna Sari Yanti
Pengaruh Kegagalan Terhadap Kinerja Chiller

Analisa Kegagalan Platen Tube SUperheater PLTU Teluk Sirih

Analisis Head Losses Pada Penstok Unit III Di Perum Jasa Tirta II Unit Jasa Pembangkit PLTA Ir. H.Djuanda

Kajian Terkait Industri Material HANKAM Dan

Kebencanaan Dari Sisi Pasar

Analisa Kerusakan Roda Gigi Cacing Pada Gearbox Air Preheater PLTU UJP Banten 3 Lontar Unit 1

Studi Eksperimental Kinerja Clod Strorage Mini dengan Refrigerant R2 dan R404A

Pengaruh Fouling Terhadap Laju Perpindahan Panas Pada Superheater Boiler CFB PLTU Sebalang

Pengaruh Jenis Pengetahuan Dan Kecakapan Terhadap Kemampuan Menulis Bahasa Inggris Pada Mahasiswa Teknik Mesin Sekolah Tinggi Teknik PLN

\begin{tabular}{|c|c|c|c|c|c|c|}
\hline$\|\mid\|$ & & SE & OLAH & VGGI TEKI & PL & \\
\hline
\end{tabular}




\title{
ANALISA KERUSAKAN RODA GIGI CACING PADA GEARBOX AIR PREHEATER PLTU UJP BANTEN 3 LONTAR UNIT 1
}

\author{
Vendy Antono \\ Jurusan S1 Teknik Mesin, Sekolah Tinggi Teknik - PLN \\ vendyantono@gmail.com \\ Arief Suardi Nur Chairat \\ Jurusan S1 Teknik Mesin, Sekolah Tinggi Teknik - PLN \\ arief.suardi@sttpln.ac.id \\ Muhammad Husnuddin \\ Jurusan S1 Teknik Mesin, Sekolah Tinggi Teknik - PLN \\ mhd.husnuddin@gmail.com
}

\begin{abstract}
Abstrak
Pada PLTU UJP Banten 3 Lontar terjadi kerusakan pada Roda Gigi Miring dalam Gearbox, dimana benda tersebut patah yang menyebabkan unit 1 berhenti beroperasi. Dari segi pengamatan visual yang terjadi dikarenakan benda kelelahan kerja, gap yang tidak merata sehingga Air Preheater bekerja dengan gesekan yang besar antara elemen yang berputar dengan seal perapat. Tidak maksimalnya putaran elemen dan motor terus memberi beban putaran, sehingga roda gigi terjadi deformasi fracture fatigue, dengan dibuktikan dari hasil pengamatan visual, uji komposisi kimia yang masih sesuai dengan standar ASTM A291, uji kekerasan sebesar 264 HB dan 282 HB diatas standar ASTM A291 sebesar 223-263 HB, uji metalografi menunjukan fasa martensit yang tidak seragam, dan SEM-EDX melihat morfologi mikrostruktur pada permukaan poros, yaitu pada beachmark, rubbings, dan rekahan akhir.
\end{abstract}

Kata kunci : PLTU, Air Preheater, Deformasi, Fracture, Fatigue, Beachmark, Rubbings, Gearbox, Roda Gigi, Komposisi Kimia, Metalografi, SEM-EDX, ASTM.

\section{PENDAHULUAN}

PLTU UJP Banten 3 Lontar salah satu dari sekian banyak pembangkit listrik di Indonesia, pembangkit ini berada di Desa Lontar Kecamatan Kemiri Kabupaten Banten Provinsi Banten. Produksi daya yang dihasilkan dari PLTU UJP Banten 3 Lontar adalah 3x315, namun dalam waktu dekat ini akan penambahan satu unit, yang nantinya daya yang dihasilkan menjadi $4 \times 315$. Dalam proses konversi energi pada pembangkit ini memerlukan bahan bakar, bahan bakar yang digunakan yaitu batu bara. Bahan bakar tersebutlah yang nantinya akan memanaskan air demineral sampai terjadinya perubahan fasa cair ke fasa uap, dari fase uap itulah kemudian akan di ekspansi ke turbin dan selanjutnya turbin menggerakan generator sehingga menghasilkan daya.

Dalam proses kerjanya daya yang dihasilkan itu tidak terlepas dari salah satu komponen utama pembangkit, yaitu boiler.
Boiler adalah suatu alat yang mengkonversi air menjadi uap kering, dalam proses tersebut dibantu oleh alat-alat bantu Forced draft fan, primary air fan, induced draft fan, mill, dan air preheater. Air Preheater adalah alat penukar kalor dari sisa pembakaran pada boiler ke udara pembakaran awal, sehingga dengan memamfaatkan kalor tersebut dapat meningkatkan effisiensi pembakaran. Selain meningkatkan effiensi pembakaran, air preheater juga menurunkan suhu pada stack dari hasil pembakaran yang tidak berdampak negatif terhadap lingkungan sekitar PLTU.

Secara sederhana prinsip kerja Air preheater yaitu dengan dibantu geraknya oleh main motor dengan ratating speed $1460 \mathrm{r} / \mathrm{min}$ dan auxiliary motor dengan rotating speed 720 $\mathrm{r} / \mathrm{min}$ yang akan menggerakan elemen-elemen. Sehingga elemen tersebut mendapatkan panas dari sisa pembakaran pada boiler dan akan di tukarkan panasnya dari udara pembakaran awal 
yang diperoleh sumber Forced Draft Fan dan Primary Air Fan.

\section{KAJIAN LITERATUR}

\subsection{Boiler}

Boiler adalah suatu alat yang merupakan bejana tertutup berfungsi sebagai pemanas air untuk kemudian dirubah menjadi uap dalam suatu siklus PLTU . Uap yang dihasilkan boiler memiliki temperatur dan tekanan sangat tinggi kemudian dipergunakan untuk pemanasan atau tenaga gerak untuk memutar turbin.

DATA TEKNIK BOILER PLTU LONTAR

$\begin{array}{ll}\text { Merk } & \text { : Dongfang } \\ \text { Type } & : \text { DG1025/17,4 } \\ \text { Main steam flow } & : 1025 \mathrm{t} / \mathrm{h} \\ \text { Main steam outlet Press } & : 17,4 \mathrm{Mpa} \\ \text { Main steam outlet Temp. } & : 541^{\circ} \mathrm{C} \\ \text { RH Flow } & : 841 \mathrm{t} / \mathrm{h} \\ \text { RH Inlet/outlet pres } & : 3,8 / 3,63 \mathrm{Mpa} \\ \text { RH Inlet/outlet Temp } & : 330 / 540{ }^{\circ} \mathrm{C} \\ \text { Feed water Temp } & : 280^{\circ} \mathrm{C}\end{array}$

\subsection{Air Preheater}

Air pre heater merupakan salah satu alat penukar kalor ( Heat Exchanger ) yang termasuk dalam kategori alat bantu dalam boiler di PLTU. Dimana berfungsi sebagai pemanas awal udara baik udara primer (Primary air) maupun sekunder (Secondary air), sampai ke tingkat temperatur tertentu sehingga dapat terjadi pembakaran optimal dalam boiler. Air Pre Heater ini menggunakan gas buang (flue gas) hasil pembakaran di boiler sebagai sumber panasnya. Gas buang hasil pembakaran pada boiler masih memiliki panas yang relative tinggi ( sekitar $500{ }^{\circ} \mathrm{C}$ ), jika langsung dibuang begitu saja pada stack maka akan berdampak buruk terhadap lingkungan sekitar. Ada dua jenis Air Preheater:

- Recuperative Air Preheater Perpindahan panas berlangsung antara flue gas dan udara melewati permukaan penukar kalor, yaitu pada umumnya berupa pipa.

- Regenerative Air Preheater Perpindahan panas berlangsung dua tahap :

1. Dari flue gas ke media penyimpan panas, biasanya berupa pelat-pelat baja.

2. Dari media penyimpan panas keudara pembakaran.

\subsection{Material}

Paduan pada baja merupakan campuran dari dua jenis logam atau lebih untuk mendapatkan sifat fisik mekanik, dan visual yang lebih baik. Sifat mekanik tidak hanya tergantung pada komposisi kimia, tetapi juga tergantung pada struktur mikronya. Suatu paduan dengan komposisi kimia yang sama dapat memiliki struktur mikro yang berbeda dan sifat mekaniknya akan berbeda, tergantung pada proses pengerjaan, terutama proses perlakuan panas selama proses pengerjaan. Jenis struktur mikro pada baja paduan yaitu:

1. Perlit (pearlite)

Campuran eutectoid dari cementite dan ferrite mempunyai kekerasan 10-30 HRC serta mengandung 0,83\% karbon. Fasa ini terjadi dibawah temperature $723^{\circ} \mathrm{C}$ atau campuran ferit dan carbide berbentuk lamel yang dihasilkan dengan cara menguraikan austenite berkomposisi eutectoid.

2. Ferit (ferrite)

Suatu komposisi logam yang mempunyai batas maksimum kelarutan karbon 0,025\% $\mathrm{C}$ pada temperatur $723^{\circ} \mathrm{C}$, struktur kristalnya BCC (Body Center Cubic) dan pada temperature kamar mempunyai batas kelarutan karbon $0,008 \%$ C. Ferit terbentuk pada proses pendinginan yang lambat dari austenite baja hipoeuktoid, ferit ini bersifat sangat lunak, ulet dan mempunyai kekerasan sekitar 70-100 BHN serta memiliki konduktivitas yang tinggi. Ferit ini mengandung senyawa trivalent yang bersifat magnetik.

3. Bainit

Dapat terbentuk apabila austenite didinginkan dengan cepat hingga mencapai temperatur tertentu (sekitar $200-400^{\circ} \mathrm{C}$ ). Transformasi bainit ini karena sebagian proses difusi dan sebagian lagi karena proses tanpa difusi.

4. Martensit

Fasa yang terjadi akibat suatu transformasi fasa yang bereaksi tanpa melibatkan pengintian dan pertumbuhan yang dicirikan dengan kontrol difusi atom. Pembentukan martensit didasari pada proses pergeseran atom yang melibatkan penyusutan dari struktur kristal. Struktur martensit merupakan konsekuensi langsung dari tegangan disekitar matriks yang timbul akibat mekanisme geser.

5. Cementite

Suatu senyawa yang terdiri dari unsur $\mathrm{Fe}$ dan $\mathrm{C}$ dengan perbandingan tertentu. 


\section{Austenite}

Suatu larutan padat yang mempunyai batas maksimum kelarutan karbon $2 \% \mathrm{C}$ pada temperatur $1130^{\circ} \mathrm{C}$, struktur kristalnya FCC (Face Center Cubic).

7. Ledeburite

Campuran eutectic antara besi gamma dengan cementite yang dibentuk pada $1130^{\circ}$ $\mathrm{C}$ dengan kandungan karbon 4,3\% C.

\subsection{Sifat material}

Sifat mekanik adalah sifat yang menyatakan kemampuan suatu material atau komponen untuk menerima beban, gaya, dan energi tanpa menimbulkan kerusakan pada material. Beberapa sifat mekanik yang penting antara lain :
1. Kekuatan (Strength
2. Kekakuan (Stiffness)
3. Kekenyalan (Elasticity)
4. Plastisitas (Plasticity)
5. Keuletan (Ductility)
6. Ketangguhan (Toughness)
7. Kegetasan (Brittleness)
8. Kelelahan (Fatigue)
9. Melar (Creep)
10. Kekerasan (Hardness)

\section{METODE PENELITIAN}

Dalam skripsi ini menggunakan metode deskriptif dimana metode ini biasa digunakan dalam penulisan laporan penelitian fakultas teknik. Metode deskriptif merupakan sebuah penelitian yang bertujuan untuk memberikan atau menjabarkan suatu keadaan atau fenomena yang terjadi saat ini dengan menggunakan prosedur ilmiah untuk menjawab masalah secara aktual (sugiyono;2011). Dengan demikian, metode penelitian deskriptif sesuai dengan penelitian yang dilaksanakan karena melakukan analisa terhadap kerusakan roda gigi miring pada gearbox Air Preheater A unit 1 PLTU UJP Banten 3 Lontar guna mengetahui penyebab terjadinya kerusakan roda gigi miring pada gearbox Air Preheater A unit 1 PLTU UJP Banten 3 Lontar.

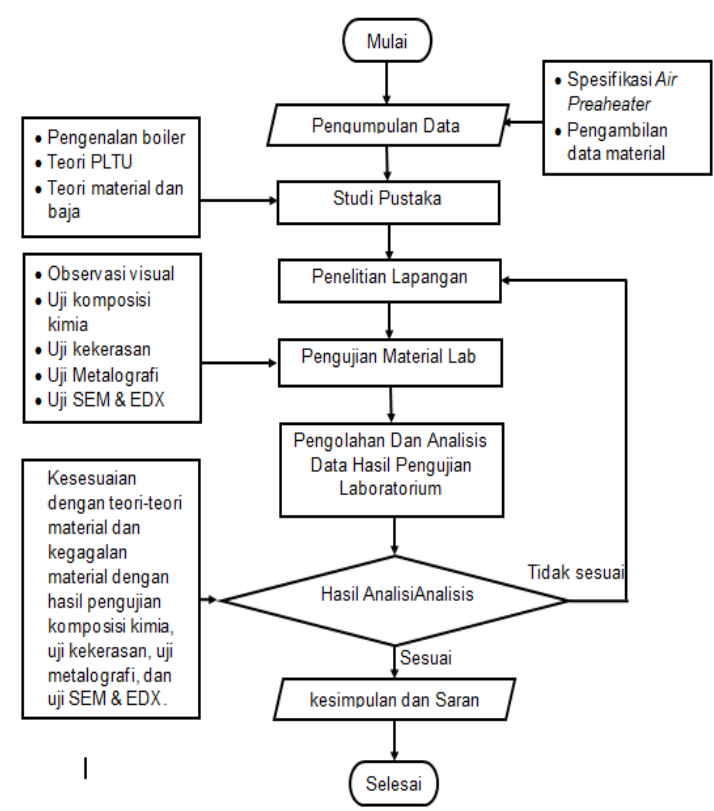

Gambar 3. Flow chart kerangka pemecahan masalah

\subsection{Teknik Pengumpulan Data}

Dalam melakukan penyelesaian penelitian ini, Penulis menggunakan beberapa cara untuk mendukung tercapainya tujuan yang telah diuraikan sebelumnya agar tercapai dengan baik dan optimal, maka diperlukan data yang akurat sebagai dasar penelitian. Data untuk dasar penelitian ini penulis dapat dengan cara sebagai berikut :

1. Pengamatan (Observasi)

Melakukan pengamatan secara langsung pada sampel Roda Gigi pada Gearbox Air Preheater PLTU UJP Banten 3 Lontar untuk mendapatkan data-data yang diperlukan untuk keperluan skripsi ini baik data tentang spesifikasi Air Preheater maupun data-data lain yang diperlukan.

2. Wawancara

Wawancara tanya jawab dengan pihakpihak yang berkompeten dalam bidang yang terkait dengan permasalahan yang dibahas.

\section{ANALISIS DAN PEMBAHASAN}

\subsection{Pengamatan Visual}

Pengamatan visual dilakukan pada area Roda Gigi Air Preheater yang mengalami kerusakan. Kerusakan roda gigi ini terjadi pada PLTU Banten 3 Lontar. Roda gigi di dalam Gearbox motor Air Preheater. Pengamatan ini dapat mengidentifikasikan jenis serta posisi pengujian yang akan dilakukan. Pada gambar 4 menunjukan kondisi kerusakan poros. 


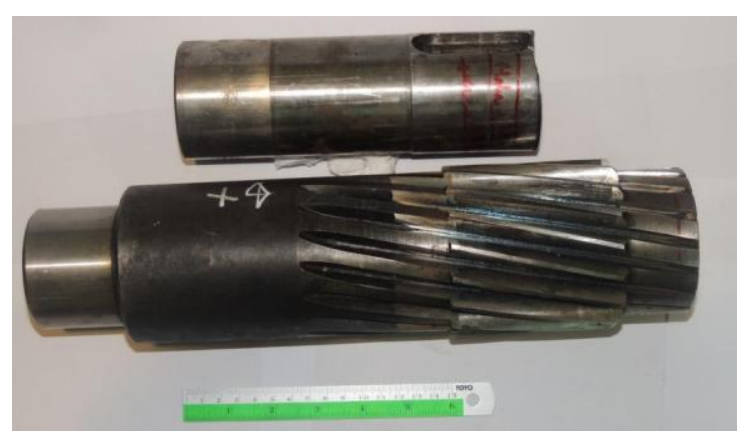

Gambar 1. Sampel Roda Gigi

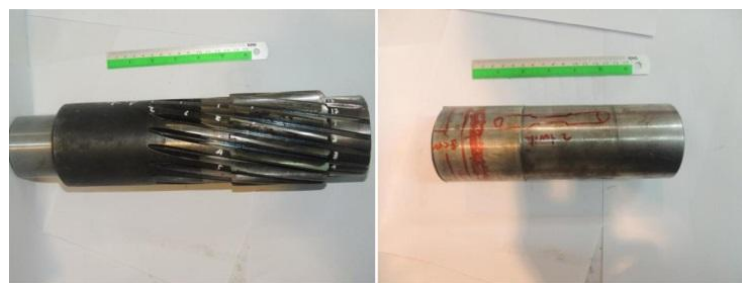

Gambar 2. Tampilan luar permukaan poros

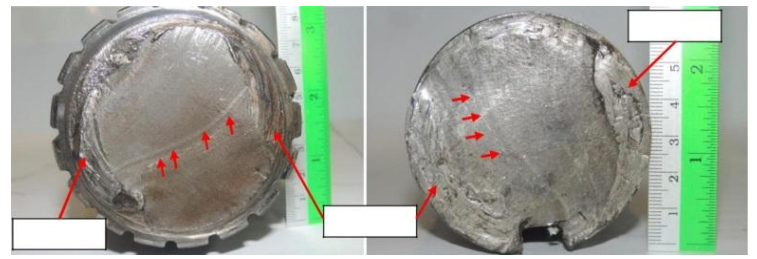

Gambar 3. Tampilan makro dari permukaan rusak

\subsection{Analisis Hasil pengujian komposisi \\ Kimia (Spectrometry)}

Pengujian komposisi kimia dilakukan untuk mengetahui kandungan komposisi kimia pada suatu material sampel poros apakah sesuai dengan standar yang berlaku dan karakter penggunaannya. Dari hasil pengujian komposisi kimia menggunakan Optical Emission Spectrometer (OES) Sampel dipotong untuk permukaan rata. Tabel 1 berisi hasil uji komposisi kimia. Rentang untuk komposisi kimia ASTM A291 "Spesifikasi Standar untuk Tempa Baja, Karbon dan Paduan, untuk Pinions, Gear dan Poros untuk Pengurangan Gears" Grade 3 Kelas C juga termasuk dalam Tabel 1 :
Tabel 1 Hasil uji komposisi kimia dibandingkan terhadap standar

\begin{tabular}{|c|c|c|}
\hline Element & Hasil Uji & $\begin{array}{c}\text { Standar material } \\
\text { dengan } \\
\text { spesifikasi } \\
\text { ASTM A291 }\end{array}$ \\
\hline Carbon & 0.192 & 0.45 max \\
\hline Manganese & 0.872 & $0.40-0.90$ \\
\hline Silicon & 0.273 & 0.35 max \\
\hline Chromium & 1.084 & 1.25 max \\
\hline Phosporous & 0.015 & 0.040 max \\
\hline Vanadium & 0.005 & 0.05 max \\
\hline Nickel & 0.057 & 0.50 max \\
\hline Sulphur & 0.013 & $0.040 \max$ \\
\hline Molybdenum & 0.229 & 0.15 min \\
\hline Copper & 0.143 & 0.35 max \\
\hline
\end{tabular}

\subsection{Analisis Hasil Pengujian Kekerasan}

Uji kekerasan poros dilakukan dengan Rockwell B hardness test (HRB) untuk memeriksa sifat mekaniknya. Tabel 2 berisi lokasi uji sampel dan hasil uji kekerasan.

Tabel 2 Data Hasil Pengujian Kekerasan.

\begin{tabular}{|c|c|c|c|}
\hline $\begin{array}{c}\text { Lokasi } \\
\text { Tes }\end{array}$ & $\begin{array}{c}\text { HRB } \\
\text { (average) }\end{array}$ & Beban & HB* \\
\hline 1 & 105 & \multirow{3}{*}{$100 \mathrm{kgf}$} & 282 \\
\hline 2 & 103 & & 264 \\
\hline 3 & 103 & & 264 \\
\hline ASTM & \multicolumn{3}{|}{} \\
A291 & \multicolumn{3}{|c}{$223-263 \mathrm{HB}$} \\
Grade 3, \\
Kelas C
\end{tabular}

\subsection{Analisis Hasil Pengujian Metallography}

Analisis struktur mikro dilakukan pada material poros dengan teknik metalografi. Analisis dilakukan pada bagian penampang dekat dengan bagian yang retak. Hasil analisisnya adalah sebagai berikut. 


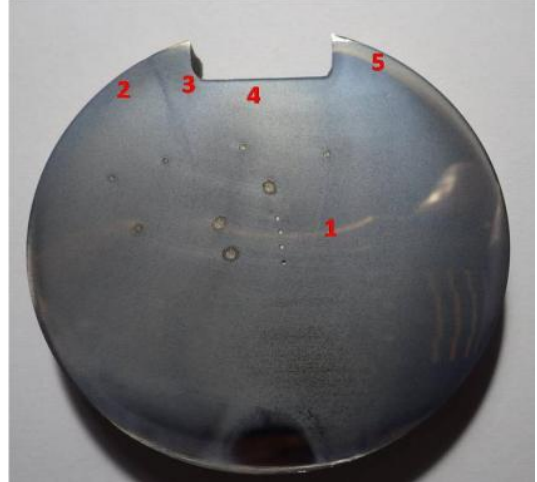

Gambar 4. Area untuk analisis struktur mikro

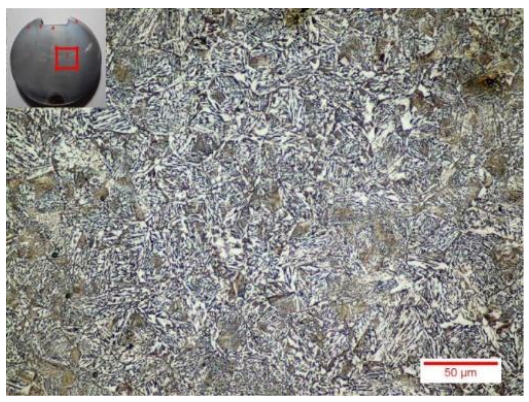

Gambar 5. Mikrostruktur pada titik 1 (inti) menunjukkan struktur perlit dengan ferit pro-eutektik (putih) (mag. 500X)

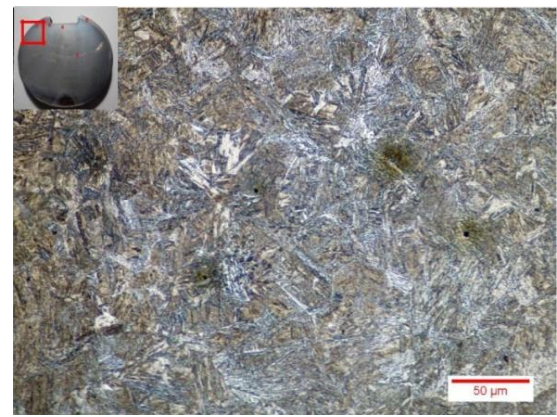

Gambar 6. Mikrostruktur pada titik 2 menunjukkan struktur perlit dengan beberapa struktur seperti jarum (mag 500X)

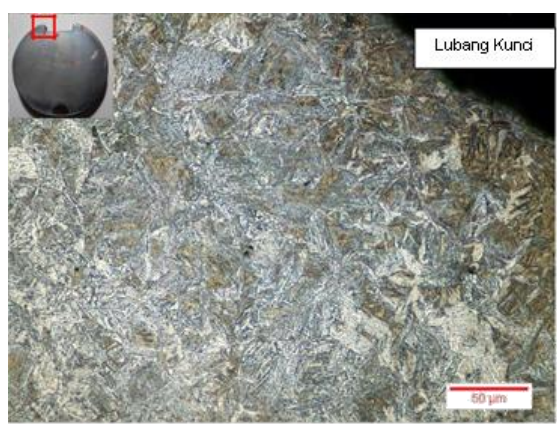

Gambar 7. Mikrostruktur pada titik 3 menunjukkan struktur perlit dengan struktur ferit pro-eutektik (putih)

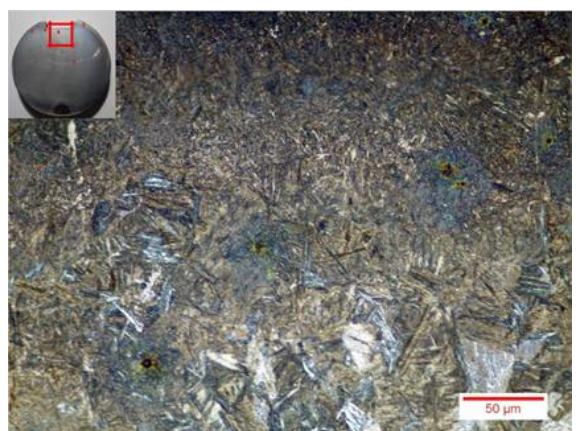

Gambar 8. Mikrostruktur pada titik 4 menunjukkan struktur perlit dengan ferit pro-eutektik (putih) dan beberapa struktur seperti jarum (mag 500X)

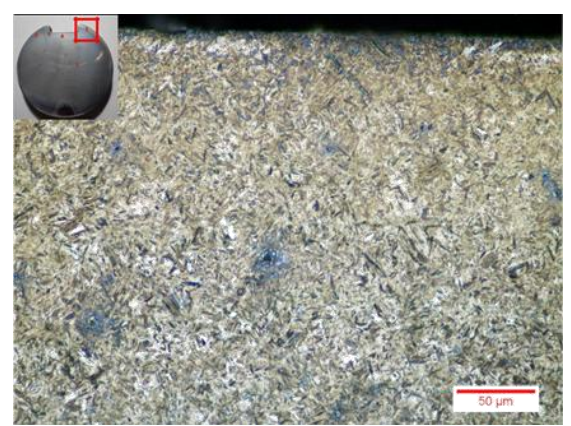

Gambar 9. Mikrostruktur pada titik 5 menunjukkan butiran halus dari struktur seperti jarum (mag 500X)

Dari analisis struktur mikro, ditemukan bahwa struktur merupakan struktur martensit yang terletak di dekat lubang kunci. Martensit ditemukan tidak seragam. Fasa tersebut akibat suatu transformasi fasa yang bereaksi tanpa melibatkan pengintian difusi atom. Pembentukan martensit didasari pada proses pergeseran atom yang melibatkan penyusutan dari struktur kristal. Struktur martensit merupakan konsekuensi langsung dari tegangan disekitar matriks yang timbul akibat mekanisme geser.

\subsection{Analisis Hasil Pengujian Sem \& Edx}

Pada pengujian ini, metode SEM (Scanning Electron Microscope) dan EDX (Energy Dispersive $X$-ray ) dilakukan di area permukaan rekahan poros untuk mengamati ciri fracture seperti pada gambar. 


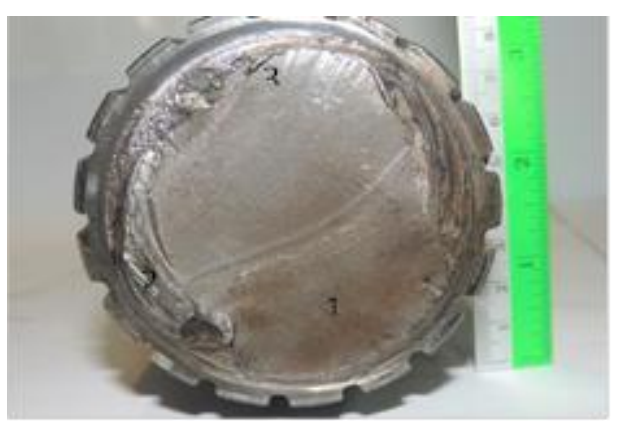

Gambar 10. Area untuk analisis SEM

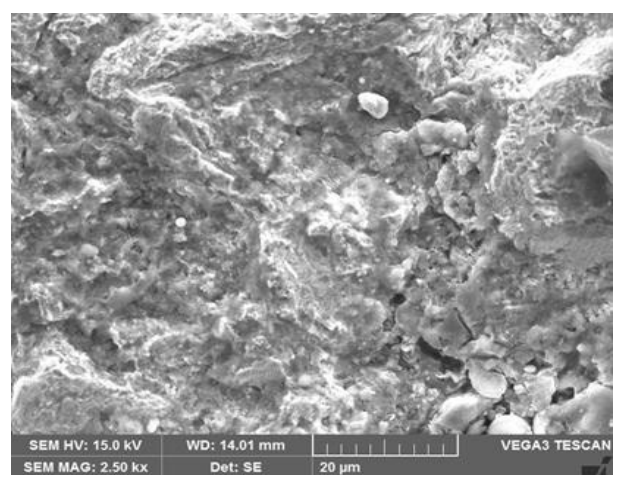

Gambar 11. Tampilan SEM dari area 1

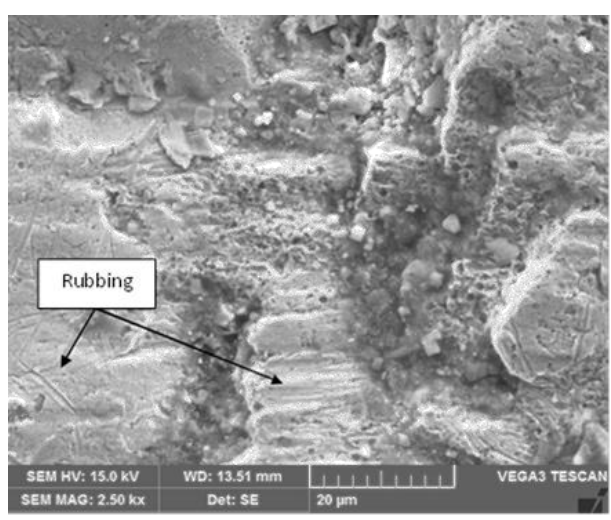

Gambar 12. Tampilan SEM area 2

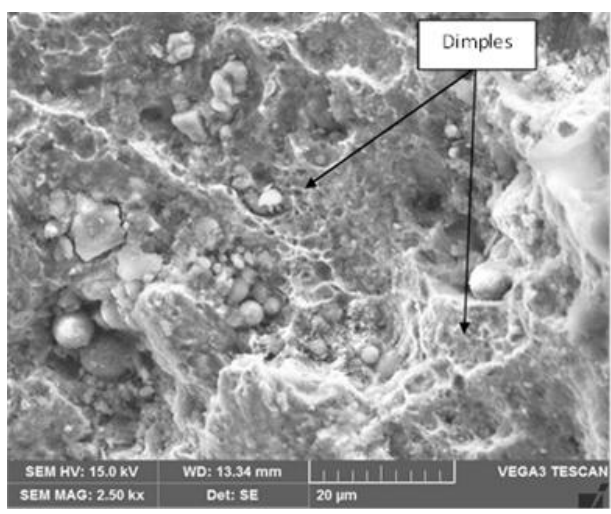

Gambar 13. Tampilan SEM area 3
Dari gambar 14, ditemukan bahwa fitur tersebut dihasilkan dari perambatan retakan transgranular dimana butir diiris dengan retak. Daerah 1 yang merupakan "beachmarks" adalah daerah perambatan yaitu transgranular. Gambar 15 menunjukkan gesekan karena kontak logam sampai logam sebelum terjadi kegagalan. Sementara itu, gambar 16 menunjukkan daerah fracture akhir yang diidentifikasi dengan adanya Dimples.

\subsection{Analisis Roda Gigi}

Hal ini di tandai dengan penemuan fracture yang sifat martensit, dimana martensit terbentuk dengan beban yang berulang-ulang, hal ini dibenarkan pada pengamatan di lapangan dari temuan Trending Ampere motor APH 1A yang hunting akibat terjadi gesekan antara radial seal dengan seal gap yang tidak merata.

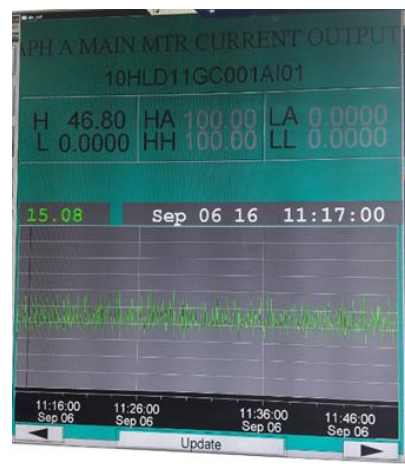

\section{Gambar 14. Tending ampere APH 1A hunting di DCS}

Dikarenakan seal gap dan radial seal tidak merata, maka putaran pada elemen tidak merata dan motor terus memberi beban yang mengakibatkan tumbukan dengan ditandai pada gambar 17 ampere yang hunting ketika terjadi tumbukan.

\section{KESIMPULAN}

Setelah dilakukan evaluasi dan analisa dari hasil pengujian maka dapat disimpulkan sebagai berikut :

1. Dari hasil pemeriksaan visual tidak menunjukkan adanya kerusakan berarti, Rubbings telah menghapus beberapa bukti, namun masih ada wilayah luas "beachmarks" yang bisa diamati.

2. Komposisi kimia poros sesuai dengan standar yang dipersyaratkan dengan standar ASTM A291 grade 3 kelas c. 
3. Nilai kekerasan sampel lebih tinggi dari standar yang dipersyaratkan ASTM A291 sebsar 223-263 HB sedangkan hasil pengujian sebesar $264 \mathrm{HB}$ dan $282 \mathrm{HB}$.

4. Dari pengujian metalografi menunjukkan fasa martensit pada sisi luar roda gigi.

5. Hasil SEM melihat lebih dalam dengan perbesaran 500x pada fracture rubbing dan dimples serta area beachmark untuk melihat fracture.

6. Hasil tersebut dinyatakan roda gigi fracture fatigue dengan pembuktian trading ampere dari APH yang hunting, sehingga poros dari roda gigi telah terjadi benturan yang sangat parah namun kemudian patah fatigue.

\section{DAFTAR PUSTAKA}

1. Ir Bambang Isty Eddi, MM. Buku panduan PLTU. STT-PLN Jakarta, 2013

2. Dieter, George E., Metalurgi Mekanik Edisi Ketiga. Terjemahan oleh Sriati Djaprie. Jakarta: Erlangga, 1986

3. French, David N, Metallurgical Failures in Fossil Fired Boilers second edition. New York : John Wiley \& Sons, Inc., 1983

4. Manual Book, Proses Bisnis Manajemen Pembangkit (2010), PT Indonesia Power

5. Adnyana. 2009. Logam dan Paduan (Metals and Alloys) Jenis \& Pembuatan. Jakarta. 